\title{
Regularity of Vibration Superposition after the Vehicle Passes through the Intermediate Straight Line between Curves
}

\author{
Biao Wang ${ }^{1}$, Kaize $\mathrm{Xie}^{1,{ }^{*}}$, Ping Wang ${ }^{1}$ and Ying $\mathrm{Zhu}^{2}$ \\ ${ }^{1}$ MOE Key Laboratory of High-speed Railway Engineering, Southwest Jiaotong University, China \\ ${ }^{2}$ China Railway Eryuan Engineering Group Co., Ltd., China \\ ${ }^{*}$ Corresponding author
}

\begin{abstract}
In order to analyze the regularity of vibration superposition after the vehicle passes through the intermediate straight line between reverse (same-sense) curves, a vertical dynamic model of vehicle-line system was established in the study First, the most unfavorable horizontal alignment combination for carbody vibration at different riding speeds and the maximum vertical vibration acceleration of carbody were determined using Genetic Algorithms (GA). And then the change characteristics of the maximum carbody vibration acceleration with the length of intermediate straight line, riding speed and superelevation gradient of transition curve in rear of intermediate straight line were analyzed. The results show that: when a vehicle travels through the reverse (same-sense) curve of most unfavorable alignment combination corresponding to different speeds, the maximum vertical carbody vibration acceleration in transition curve in rear of intermediate line will increase with the riding speed. Within a certain length, longer intermediate straight line may not help mitigating the superposition effect of carbody vibration, and greater riding speed do not necessarily result in greater vertical carbody vibration. The maximum vertical vibration acceleration of carbody when the train travels in reverse (same-sense) curve follows the same attenuation rule. It attenuates as per the natural vibration period and stabilizes basically after two periods. The maximum vibration acceleration of carbody after stabilization increases with enlarging the riding speed and the superelevation gradient of the transition curve in rear of intermediate straight line; further, the maximum vibration accelerations of carbody at the same riding speeds and superelevation gradients are the same.
\end{abstract}

Keywords-intermediate straight line; regularity of vibration superposition; genetic algorithms; horizontal alignment combination; vehicle-line vibration model

\section{INTRODUCTION}

For the sake of continuity and good riding quality of a railway line, a straight line of certain length shall be interposed between two adjoining curves. This straight line, connecting the ending point of the front curve and the starting point of the rear curve, is called intermediate straight line [1]. As specified in the railway line design codes in many nations, the length of intermediate straight line is calculated using non-superposition theory of carbody vibration. The basic idea is that the impact of wheel on rail at spiral to tangent (ST) and tangent to spiral (TS) will cause vibration of carbody when a train travels in the intermediate straight line. For the purpose of avoiding vibration superposition and ensuring riding comfort, this intermediate straight line shall be long enough, so that the traveling time (t) of the train in the intermediate straight line at the highest riding speed shall not be below the vibration disappearing time of the bogie spring. Based on practical experiences and field tests, relevant criteria for the minimum length of intermediate straight line have been developed in various nations using nonsuperposition theory of vibration, such as $0.67 \mathrm{Vmax}$ by TGV in France, $0.6 \mathrm{Vmax}$ by ICE in Germany [2] and $0.6 \mathrm{Vmax}$ in China [3].

Railway line dynamics has been adequately studied throughout the world. Among these studies, QIU Fei-jian [4] related the riding comfort to intermediate straight line, and discussed the selection of railway line parameters in terms of railway dynamics. X-Y Long analyzed the basic requirements for transition curves and clarified the forms in transition curves, and developed a dynamic model to simulate six representative types of transition curve [5]. JH Um presented a method to optimize the linetype of horizontal curves to enhance train riding comfort and riding quality when horizontal and vertical curves are superimposed in the case of railway construction/renovation [6]. Z.Krzyszoto [7] studied the influencing regularity of curve radii, superelevation and riding speed on dynamic performance of vehicle traveling in circular curves. KMiyagaki [8] systematically analyzed the impact of linetype of transition curves on dynamic response of vehicle from perspectives of frequency domain and time domain, and put forward new linetype for transition curve. GAO Liang et al. [9] developed a model of continuously welded track (CWR) turnout group with finite element method, and analyzed the impact of the intermediate straight line of the minimum length between turnouts on the stress and deformation of the turnouts.

However, the existing vibration non-superposition theory is somewhat subjective, and cannot objectively demonstrate the vibration superposition phenomenon and regularity when a train travels in intermediate straight line. In this paper, the regularity of vibration superposition response after the train passes through the intermediate straight line was studied here by combining Genetic Algorithms (GA) and vehicle-line dynamics. 


\section{Vehicle-Line CALCUlation Model AND ITS PARAMETERS}

\section{A. Calculation Model}

The characteristics of vertical vibration of carbody when a train travels in reverse (same-sense) curve were considered solely in the study, so the full-vehicle plane calculation model (Figure 1) was adopted. The model is based on the assumptions below: the carbody has two degree of freedoms (DOFs), i.e. vertical movement and pitch, the spring stiffness and damping of secondary suspension is considered between carbody and bogie; while the bogie also has vertical movement and pitch, and the spring stiffness and damping of primary suspension is considered between bogie and wheel. It is assumed that the wheel clings to the rail surface during vibration, the wheel displacement and the height of rail alignment plane are equal, and the wheel has no DOFs. Then a full vehicle plane model of six DOFs and rigid track was established for vertical vibration analysis. Alignment parameters were incorporated into integrated dynamic equation as irregularities, and the alignment parameter samples of each generation could be generated automatically within the scope of constraints, so that these parameters could be re-inputted into the vehicle-line dynamic model for calculation of next generation, following relevant processes of selection, crossover, mutation, etc. in the GA.

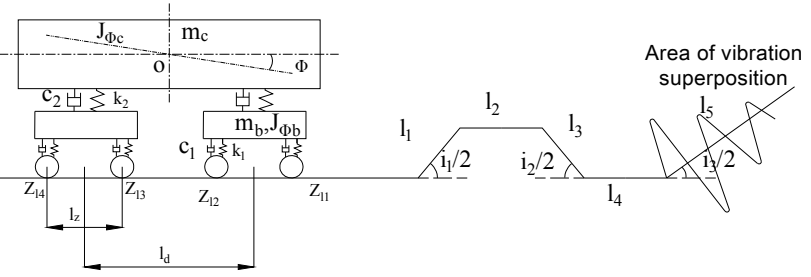

FIGURE I. CALCULATION MODEL FOR VEHICLE-LINE VIBRATION

In Figure $1, \mathrm{~m}_{\mathrm{c}}, \mathrm{J}_{\Phi \mathrm{c}}=$ Weight and pitch inertia of carbody, respectively; $\mathrm{m}_{\mathrm{b}}, \mathrm{J}_{\Phi \mathrm{b}}=$ Weight and pitch inertia of bogie, respectively; $\mathrm{c}_{1}, \mathrm{k}_{1}=$ Spring stiffness and damping of primary suspension, respectively; $\mathrm{c}_{2}, \mathrm{k}_{2}=$ Spring stiffness and damping of secondary suspension, respectively; $l_{d}=$ Length between truck pivot centers; $1_{z}=$ Bogie wheelbase; $Z_{11}, Z_{12}, Z_{13}, Z_{14}=$ Vertical displacements at four wheelsets; $1_{1}=$ Length of transition curve 1 of front curves; $1_{2}=$ Length of circular curve of front curves; $l_{3}=$ Length of transition curve 2 of front curves $; 1_{4}=$ Length of intermediate straight line; $1_{5}=$ Length of transition curve 1 of rear curves; $i_{1}, i_{2}, i_{3}=$ superelevation gradients of corresponding transition curves.

Previous studies demonstrate that vibration superposition effect when the carbody travels in intermediate straight line is mainly manifested in the transition curve segment in rear of the intermediate straight line [10], i.e. $1_{5}$ in Figure 1. Therefore, irrespective of the length constraint of $1_{5}$ and assuming it to be infinitely long in the model, vertical vibration characteristics of carbody in the transition curve in rear of intermediate straight line were studied for intermediate straight lines of different lengths.

The generalized equation for vertical vehicle-line dynamic model can be expressed in the following form:

$$
\left\{\begin{array}{c}
{[M]\left\{\ddot{X}_{i}\right\}+[C]\left\{\dot{X}_{i}\right\}+[K]\left\{X_{i}\right\}=\left\{Q_{i}\right\}} \\
Q_{i}=f\left(\{11,12,13,14,15, i 1, i 2, i 3\}_{i}\right)
\end{array}\right.
$$

Where,[M], [C] and [K] denote weight, damping and stiffness matrixes respectively; $\left\{\ddot{X}_{i}\right\},\left\{\dot{X}_{i}\right\}$ and $\left\{X_{i}\right\}$ denote generalized displacement, generalized speed and generalized acceleration of the ith generation in the GA, respectively; $\left\{1_{1}, 1_{2}, 1_{3}, 1_{4}, 1_{5}, i_{1}, i_{2}, i_{3}\right\}_{i}$ is the alignment parameter sample of the $i$ th generation.

\section{B. Model Parameters}

CRH2 electric multiple unit (EMU) model was used to model the vehicle with parameters as listed in Table 1.

TABLE I. PARAMETERS OF VEHICLE MODEL

\begin{tabular}{|c|c|c|}
\hline Description & Unit & CRH2 EMU \\
\hline Weight of carbody & $\mathrm{kg}$ & 31600 \\
\hline Weight of bogie & $\mathrm{kg}$ & 3200 \\
\hline Pitch inertia of carbody & $\mathrm{kg} \cdot \mathrm{m}^{2}$ & 1548400 \\
\hline Pitch inertia of bogie & $\mathrm{kg} \cdot \mathrm{m}^{2}$ & 1752 \\
\hline Stiffness of primary suspension & $\mathrm{N} / \mathrm{m}$ & $1.176 \mathrm{e} 6$ \\
\hline Stiffness of secondary suspension & $\mathrm{N} / \mathrm{m}$ & $1.1456 \mathrm{e} 6$ \\
\hline Damping of primary suspension & $\mathrm{N} \cdot \mathrm{s} / \mathrm{m}$ & 25000 \\
\hline Damping of secondary suspension & $\mathrm{N} \cdot \mathrm{s} / \mathrm{m}$ & 120000 \\
\hline Length between truck pivot centers & $\mathrm{m}$ & 18 \\
\hline Bogie wheelbase & $\mathrm{m}$ & 2.5 \\
\hline
\end{tabular}

Alignment parameters were determined by referring to Code for Design of Railway Line (draft for approval), in which the scope of common curve radii for $200 \mathrm{~km} / \mathrm{h}$ passenger/goods mixed railway was taken as $[2800 \mathrm{~m}, 6000 \mathrm{~m}]$, and the scope of other parameters was thereby defined (allowable deficient superelevation: general $-70 \mathrm{~mm}$, difficult $-90 \mathrm{~mm}$; allowable surplus superelevation: general - 40mm, difficult - 60mm) [11] The finalized scope of alignment parameters is shown in Table 2 .

TABLE II. SCOPE OF ALIGNMENT PARAMETERS

\begin{tabular}{|c|c|c|c|}
\hline \multirow{2}{*}{ Symbol } & Description & \multicolumn{2}{c|}{ Scope of Parameters } \\
\cline { 3 - 4 } & $\begin{array}{c}\text { Lower } \\
\text { limit (-) }\end{array}$ & $\begin{array}{c}\text { Upper } \\
\text { limit (+) }\end{array}$ \\
\hline $1_{1}$ & $\begin{array}{c}\text { Length of transition curve 1 of front } \\
\text { curves }\end{array}$ & $80 \mathrm{~m}$ & $200 \mathrm{~m}$ \\
\hline $1_{2}$ & $\begin{array}{c}\text { Length of circular curve of front } \\
\text { curves }\end{array}$ & $100 \mathrm{~m}$ & $180 \mathrm{~m}$ \\
\hline $1_{3}$ & $\begin{array}{c}\text { Length of transition curve 2 of front } \\
\text { curves }\end{array}$ & $80 \mathrm{~m}$ & $200 \mathrm{~m}$ \\
\hline $1_{4}$ & Length of intermediate straight line & 0 & $180 \mathrm{~m}$ \\
\hline $\mathrm{i}_{1} / 2$ & $\begin{array}{c}1 / 2 \text { of superelevation gradient of } \\
\text { transition curve 1 }\end{array}$ & 0 & $0.6 \% 0$ \\
\hline $\mathrm{i}_{2} / 2$ & $\begin{array}{c}1 / 2 \text { of superelevation gradient of } \\
\text { transition curve 2 }\end{array}$ & 0 & $0.6 \%$ \\
\hline $\mathrm{i}_{3} / 2$ & $\begin{array}{c}1 / 2 \text { of superelevation gradient of } \\
\text { transition curve 1 }\end{array}$ & 0 & $0.6 \% \mathrm{Inf}$ \\
\hline $\mathrm{t}$ & $\begin{array}{c}\text { Traveling time of carbody in } \\
\text { transition curve 3 }\end{array}$ & 0 & Inf \\
\hline
\end{tabular}

In Table 2, (i/2)max is solved as per the following process: obtaining the maximum actual superelevation from the scope 
of radii and surplus superelevation, which is $100 \mathrm{~mm}$; and then obtaining the results with $(\mathrm{i} / 2) \max =$ the maximum actual superelevation /(minimum length of transition curve $* 2)=100 \mathrm{~mm} /(80 \mathrm{~m} * 2)=0.625 \% \approx 0.6 \%$.

The following constraint condition shall be met at the same time.

$$
\lambda 1 * 11-\lambda 3 * 12=0
$$

III. DETERMINING THE MOST UNFAVORABLE HORIZONTAL ALIGNMENT COMBINATION FOR VERTICAL VIBRATION OF CARBODY BASED ON GA

The determination of the most unfavorable length of intermediate straight line could be viewed as an optimization issue of horizontal alignment parameters of reverse (same sense) curve, for the maximum vibration acceleration of carbody in the transition curve in rear of intermediate straight line. The Genetic Algorithm (GA) is an adaptive global optimal searching algorithm based on Darwin's nature evolution theory and Mendel's genetics and mutation theory [12]. It mimics the process of biological evolution and can solve large scale problems effectively, deal with discrete variables and determine the optimal solution for the function with multiple local minima [13]. In this section, the most unfavorable horizontal alignment combination for vertical vibration of carbody was determined by combining GA and abovementioned vehicle-line vibration model.

\section{A. Determination of the Most Unfavorable Horizontal Alignment Combination Based on GA}

1) Fitness function: The objective function in the paper is the maximum absolute value $(\mathrm{a}(\mathrm{t}))$ of vibration acceleration in transition curve in rear of intermediate straight line, so the fitness function is written as abs $(\mathrm{a}(\mathrm{t}))$.

2) Control parameters: Real-value encoding GA was adopted in the study. Michalewicz found out that the application of floating-point encoding GA to function optimization was more accurate and efficient; however, realvalue encoding GA outperformed binary encoding GA in high mutation rate case, as the former improved the searching capability in searching space without adversely affecting convergence characteristics. The initial population was made up of randomly selected individuals distributed uniformly. The number of evolution generations Generation $=50$; the size of population $\mathrm{N}=100$; crossover rate $\mathrm{Pc}=0.8$; mutation rate $\mathrm{Pm}=0.03$. Stochastic universal sampling and multi-point crossover were adopted.

3) Constrained conditions: Constrained conditions can be found in Table2 and (2).

When a CRH2 electric multiple unit (EMU) travels in reverse (same-sense) curve at $200 \mathrm{~km} / \mathrm{h}, 160 \mathrm{~km} / \mathrm{m}$ and $120 \mathrm{~km} / \mathrm{h}$ respectively, the evolution process of the maximum vibration acceleration of carbody induced by line parameters combination of each generation is as shown in Figure 2.

As can be seen from Figure 2, the evolution process has good convergence performance and ensures the population diversity in the meantime.

The most unfavorable horizontal alignment combination of the reverse (same-sense) curve here, and corresponding maximum vertical vibration acceleration of carbody are shown in Table 3.

TABLE III. INDEPENDENT VARIABLES CORRESPONDING TO THE BEST SOLUTIONS

\begin{tabular}{|c|c|c|c|c|c|c|c|c|c|c|}
\hline $\begin{array}{c}\text { Riding Speed } \\
\mathbf{( k m} / \mathbf{h})\end{array}$ & $\mathbf{l}_{\mathbf{1}}(\mathbf{m})$ & $\mathbf{l}_{\mathbf{2}}(\mathbf{m})$ & $\mathbf{l}_{\mathbf{3}}(\mathbf{m})$ & $\mathbf{l}_{\mathbf{4}}(\mathbf{m})$ & $\mathbf{i}_{\mathbf{1}} / \mathbf{2}\left(\mathbf{\%}_{0}\right)$ & $\mathbf{i}_{\mathbf{2}} / \mathbf{2}\left(\%_{0}\right)$ & & $\mathbf{i}_{3} / \mathbf{2}\left(\mathbf{\%}_{0}\right)$ & $\mathbf{t}(\mathbf{s})$ & $\begin{array}{c}\text { Maximum } \\
\text { Acceleration }\left(\mathbf{m} / \mathbf{s}^{\mathbf{2}}\right)\end{array}$ \\
\hline 200 & 152.01 & 127.66 & 93.97 & 0.65 & 0.4 & 0.6 & & 0.6 & 0.1422 & 0.336 \\
\hline 160 & 109.80 & 103.29 & 80.07 & 0.45 & 0.5 & 0.6 & & 0.6 & 0.1327 & 0.270 \\
\hline 120 & 96.53 & 104.82 & 94.99 & 0 & 0.6 & 0.6 & & 0.6 & 0.1483 & \\
\hline
\end{tabular}

As shown in Table 3 that, under the most unfavorable horizontal alignment combinations corresponding to different riding speeds, the maximum vertical vibration of carbody traveling in transition curve in rear of intermediate straight line under superposition effect will increase with the riding speed. The maximum vertical vibration acceleration of carbody is $0.336 \mathrm{~m} / \mathrm{s}^{2}$.

\section{Change Regularity OF VERTICAL ACCELERATION OF CARBODY WITH THE LENGTH OF INTERMEDIATE STRAIGHT LINE}

A. Change Regularity of Carbody Vibration Acceleration with the Length of Intermediate Straight Line at Different Riding Speeds

Figure 3 shows the change regularity of vertical vibration acceleration with the length of intermediate straight line at different riding speeds under the most unfavorable horizontal alignment combination for riding speed of $200 \mathrm{~km} / \mathrm{h}$. Figure 5 depicts the change regularity of the maximum vertical vibration acceleration of carbody with the length of intermediate straight line at different riding speeds under the most unfavorable horizontal alignment combinations for three different riding speeds.

Figure 3(A) shows the change regularity of vertical vibration acceleration with the length of intermediate straight line at different riding speeds under the most unfavorable horizontal alignment combination for riding speed of $200 \mathrm{~km} / \mathrm{h}$. Figure 3(B) depicts the change regularity of the maximum vertical vibration acceleration of carbody with the length of intermediate straight line at different riding speeds under the 
most unfavorable horizontal alignment combinations for three different riding speeds.

As shown in Figures 4, the maximum superimposed vibration induced by vertical vibration of carbody near the intermediate straight line does not simply decrease with increasing the length of intermediate straight line, but fluctuates periodically, i.e. within a certain length, longer intermediate straight line may not help mitigating the superposition effect of carbody vibration. For instance, when a $\mathrm{CRH} 2 \mathrm{EMU}$ travels at $200 \mathrm{~km} / \mathrm{h}$ in the intermediate straight line of $25 \mathrm{~m}$ long, the vertical vibration acceleration of carbody is $0.09 \mathrm{~m} / \mathrm{s}^{2}$; however, when the train travels at the intermediate straight line of $55 \mathrm{~m}$ long, the maximum vibration acceleration will be $0.19 \mathrm{~m} / \mathrm{s}^{2}$, increasing by $110 \%$ against the former case.

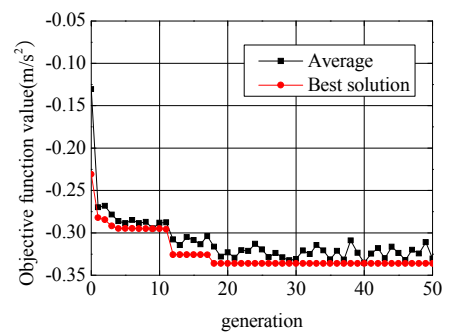

(A) $200 \mathrm{~km} / \mathrm{H}$

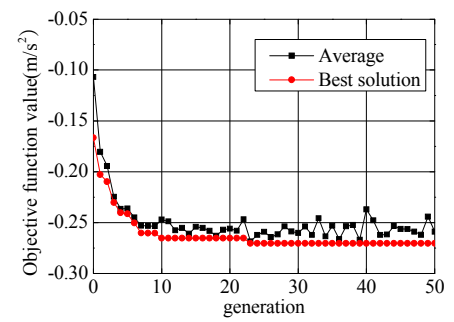

(B) $160 \mathrm{~km} / \mathrm{H}$

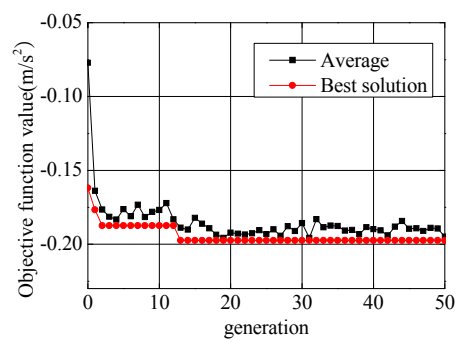

(C) $120 \mathrm{~km} / \mathrm{H}$

FIGURE II. OBJECTIVE FUNCTION VALUE AND PERFORMANCE TRACKING DURING OPTIMIZATION

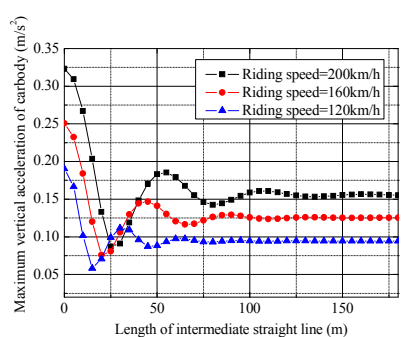

(A) AT RIDING SPEED OF $200 \mathrm{KM} / \mathrm{H}$

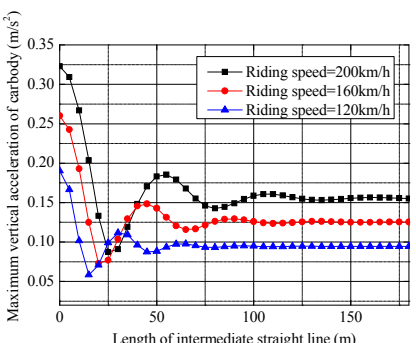

(B) AT THREE DIFFERENT RIDING SPEEDS

FIGURE III. THE MOST UNFAVORABLE HORIZONTAL ALIGNMENT COMBINATION

For the layout of the same or different horizontal alignment combinations, given a certain length of intermediate straight line, higher riding speed does not necessarily relate to greater vertical vibration acceleration of carbody. For the two different alignment combinations in Figures 3(A) and (B), viz. the most unfavorable horizontal alignment combination for riding speed of $200 \mathrm{~km} / \mathrm{h}$ and that for three different riding speeds, given a $30 \mathrm{~m}$-long intermediate straight line, the maximum vertical vibration acceleration of carbody follows the relation of: $120 \mathrm{~km} / \mathrm{h}>160 \mathrm{~km} / \mathrm{h}>200 \mathrm{~km} / \mathrm{h}$ for both cases.

\section{B. Change Regularity of Carbody Vibration Acceleration with the Traveling Time in Intermediate Straight Line at Different Riding Speeds}

Figure 4(A) shows the change regularity of the maximum vertical vibration acceleration with the traveling time in intermediate straight line at different riding speeds, under the most unfavorable horizontal alignment combination for riding speed of $200 \mathrm{~km} / \mathrm{h}$. Figure 4 (B) depicts the change regularity of the maximum vertical vibration acceleration of carbody with the traveling time in intermediate straight line at different riding speeds, under the most unfavorable horizontal alignment combinations for three different riding speeds.

As can be seen from Figures 4, when a train travels at different speeds in the curves under the two cases, the maximum vertical vibration accelerations of carbody in transition curve follow the same attenuation regularity with the same attenuation period, i.e. about $0.93 \mathrm{~s}$, equaling to the natural vibration period of carbody. At different riding speeds and under different alignment combinations, the vertical movement of carbody near the intermediate straight line subsides in about $1.86 \mathrm{~s}$ (about two natural vibration periods of carbody). In what follows, to justify the results and determine reasonable layout of intermediate straight line, the change regularities of the maximum vertical vibration acceleration of carbody under different random horizontal alignment combinations and lengths of intermediate straight line were analyzed in detail. 


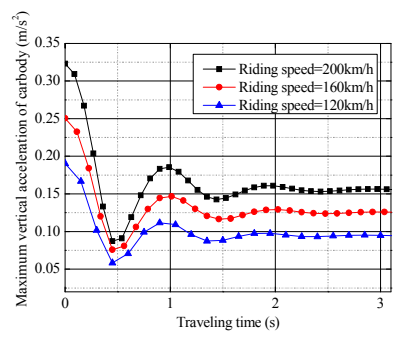

(A) AT RIDING SPEED OF $200 \mathrm{KM} / \mathrm{H}$

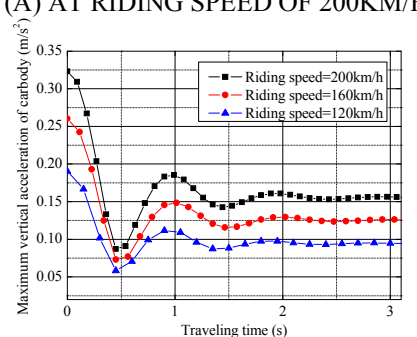

(B) AT THREE DIFFERENT RIDING SPEEDS

FIGURE IV. THE MOST UNFAVORABLE HORIZONTAL ALIGNMENT COMBINATION

\section{Change Regularity of Vertical Vibration Acceleration of Carbody with the Length of Intermediate Straight Line Under Random Alignment Combinations}

Ten alignment combinations (Table 4) were randomly generated based on uniform distribution within the constraint conditions listed in Table 2.

TABLE IV. RANDOM ALIGNMENT COMBINATIONS

\begin{tabular}{|c|c|c|c|c|c|c|c|}
\hline 8 & $l_{1}(\mathrm{~m})$ & $\mathrm{l}_{2}(\mathrm{~m})$ & $\mathrm{l}_{3}(\mathrm{~m})$ & $\mathrm{i}_{1} / 2$ & $\mathrm{i}_{2} / 2$ & $\mathrm{i}_{3} / 2$ & $1_{4}(\mathrm{~m})$ \\
\hline $\begin{array}{c}\text { Random } \\
\text { combination } \\
1 \\
\end{array}$ & $\begin{array}{c}173 . \\
63\end{array}$ & $\begin{array}{c}118 . \\
78\end{array}$ & $\begin{array}{c}145 . \\
64\end{array}$ & $\begin{array}{l}0.5 \\
\% 0\end{array}$ & $\begin{array}{l}0.6 \\
\% 0\end{array}$ & $\begin{array}{c}0.4 \\
\% 0\end{array}$ & $\begin{array}{c}0- \\
180\end{array}$ \\
\hline $\begin{array}{c}\text { Random } \\
\text { combination } \\
2 \\
\end{array}$ & $\begin{array}{c}126 . \\
76\end{array}$ & $\begin{array}{c}128 . \\
25\end{array}$ & $\begin{array}{c}115 . \\
55\end{array}$ & $\begin{array}{l}0.4 \\
\% 0\end{array}$ & $\begin{array}{l}0.5 \\
\% 0\end{array}$ & $\begin{array}{l}0.2 \\
\% 0\end{array}$ & \\
\hline $\begin{array}{c}\text { Random } \\
\text { combination } \\
3 \\
\end{array}$ & $\begin{array}{c}109 . \\
00\end{array}$ & $\begin{array}{c}165 . \\
69\end{array}$ & $\begin{array}{c}169 \\
36\end{array}$ & $\begin{array}{l}0.5 \\
\% 0\end{array}$ & $\begin{array}{l}0.3 \\
\% 0\end{array}$ & $\begin{array}{l}0.5 \\
\% 0\end{array}$ & \\
\hline $\begin{array}{c}\text { Random } \\
\text { combination } \\
4 \\
\end{array}$ & $\begin{array}{c}128 . \\
46\end{array}$ & $\begin{array}{c}101 \\
23\end{array}$ & $\begin{array}{c}102 . \\
67\end{array}$ & $\begin{array}{l}0.2 \\
\% 0\end{array}$ & $\begin{array}{l}0.3 \\
\% 0\end{array}$ & $\begin{array}{c}0.3 \\
\% 0\end{array}$ & \\
\hline $\begin{array}{c}\text { Random } \\
\text { combination } \\
5 \\
\end{array}$ & $\begin{array}{c}91.5 \\
7\end{array}$ & $\begin{array}{c}103 . \\
44\end{array}$ & $\begin{array}{c}162 . \\
41\end{array}$ & $\begin{array}{l}0.5 \\
\% 0\end{array}$ & $\begin{array}{l}0.3 \\
\% 0\end{array}$ & $\begin{array}{c}0.2 \\
\% 0\end{array}$ & \\
\hline $\begin{array}{c}\text { Random } \\
\text { combination } \\
6\end{array}$ & $\begin{array}{c}95.8 \\
3\end{array}$ & $\begin{array}{c}113 . \\
51\end{array}$ & $\begin{array}{c}102 . \\
02\end{array}$ & $\begin{array}{l}0.2 \\
\% 0\end{array}$ & $\begin{array}{l}0.2 \\
\% 0\end{array}$ & $\begin{array}{c}0.6 \\
\% 0\end{array}$ & \\
\hline $\begin{array}{c}\text { Random } \\
\text { combination } \\
7\end{array}$ & $\begin{array}{c}193 . \\
04\end{array}$ & $\begin{array}{c}151 . \\
92\end{array}$ & $\begin{array}{c}124 . \\
21\end{array}$ & $\begin{array}{l}0.2 \\
\% 0\end{array}$ & $\begin{array}{c}0.3 \\
\% 0\end{array}$ & $\begin{array}{l}0.5 \\
\% 0\end{array}$ & \\
\hline $\begin{array}{c}\text { Random } \\
\text { combination } \\
8 \\
\end{array}$ & $\begin{array}{c}194 . \\
73\end{array}$ & $\begin{array}{c}158 . \\
53\end{array}$ & $\begin{array}{c}155 . \\
07\end{array}$ & $\begin{array}{l}0.2 \\
\% 0\end{array}$ & $\begin{array}{l}0.3 \\
\% 0\end{array}$ & $\begin{array}{c}0.3 \\
\% 0\end{array}$ & \\
\hline $\begin{array}{c}\text { Random } \\
\text { combination } \\
9 \\
\end{array}$ & $\begin{array}{c}149 . \\
02\end{array}$ & $\begin{array}{c}151 . \\
81\end{array}$ & $\begin{array}{c}173 . \\
62\end{array}$ & $\begin{array}{c}0.6 \\
\% 0\end{array}$ & $\begin{array}{l}0.5 \\
\% 0\end{array}$ & $\begin{array}{c}0.4 \\
\% 0\end{array}$ & \\
\hline $\begin{array}{c}\text { Random } \\
\text { combination } \\
10\end{array}$ & $\begin{array}{c}87.1 \\
7\end{array}$ & $\begin{array}{c}136 . \\
07\end{array}$ & $\begin{array}{c}89.7 \\
3\end{array}$ & $\begin{array}{l}0.5 \\
\% 0\end{array}$ & $\begin{array}{l}0.5 \\
\% 0\end{array}$ & $\begin{array}{c}0.4 \\
\% 0\end{array}$ & \\
\hline
\end{tabular}

The change regularity of vertical vibration of carbody with the length of intermediate straight line for the layout of different horizontal alignment combinations is as shown in Figure 5.

As shown in Figure 5, the variation trend of maximum vertical vibration acceleration of carbody with the length of intermediate straight line is basically the same at different riding speeds and under different horizontal alignment combinations. Moreover, the acceleration subsides when the length of intermediate straight line is longer than $\mathrm{V}^{*} 1.86 \mathrm{~s}$ (about two natural frequency periods of carbody).
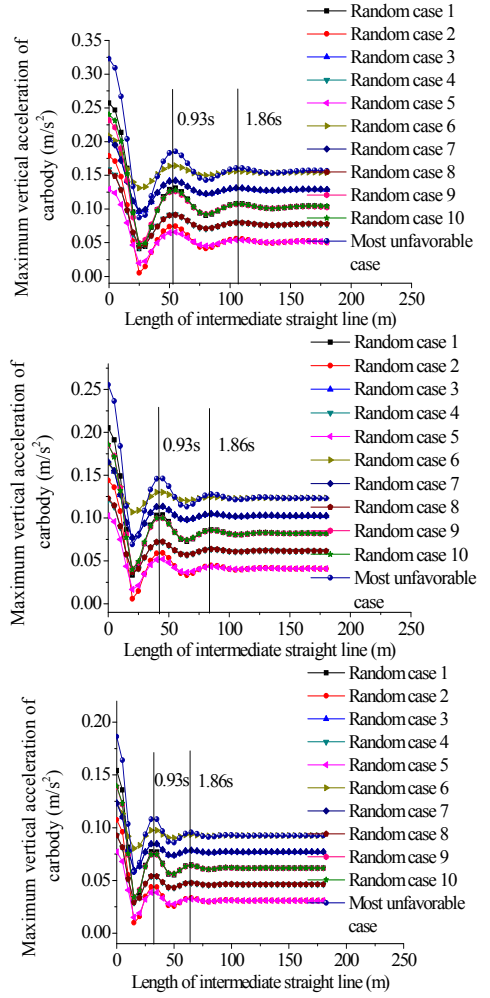

FIGURE V. CHANGE REGULARITY OF VERTICAL VIBRATION ACCELERATION OF CARBODY WITH THE LENGTH OF INTERMEDIATE STRAIGHT LINE FOR RANDOM ALIGNMENT COMBINATIONS: (A) $200 \mathrm{KM} / \mathrm{H}$; (B) $160 \mathrm{KM} / \mathrm{H}$; (C) $120 \mathrm{KM} / \mathrm{H}$

In this case, the maximum vertical vibration acceleration of carbody depends on the riding speed and superelevation gradient of rear transition curve. In the randomly generated horizontal alignment combinations, there are five types of superelevation gradients of rear transition curve, including $0.2 \% 0,0.3 \%$, $0.4 \%$, $0.5 \%$ and $0.6 \%$. At different riding speeds, the maximum vertical vibration accelerations of carbody for the same superelevation gradient of transition curve in rear of intermediate line are the same. And it will increase with increasing the riding speed and superelevation gradient.

\section{CONCLUSIONS}

The following conclusions can be drawn from above analysis: 
(1) When a CRH2 EMU travels at $120 \mathrm{~km} / \mathrm{h}, 160 \mathrm{~km} / \mathrm{h}$ and $200 \mathrm{~km} / \mathrm{h}$ respectively in the reverse (same-sense) curve of the most unfavorable horizontal alignment combination corresponding to each riding speed, the vertical vibration acceleration in the transition curve in rear of intermediate straight line increases with the riding speed, and the maximum vertical vibration accelerations of carbody are $0.197 \mathrm{~m} / \mathrm{s}^{2}, 0.27$ $\mathrm{m} / \mathrm{s}^{2}$ and $0.336 \mathrm{~m} / \mathrm{s}^{2}$ respectively for the three speeds.

(2) The maximum superposition effect of vertical vibration acceleration of carbody adjacent to the intermediate straight line does not simply reduce with increasing the length of intermediate straight line, but fluctuates periodically, i.e. within a certain length, longer intermediate straight line may not help mitigating the superposition effect of carbody vibration.

(3) Given a certain length of intermediate straight line, higher riding speed does not necessarily relate to greater vertical vibration of carbody.

(4) When a train travels at different speeds in the curves of different horizontal alignment combinations, the maximum vertical vibration accelerations of carbody follow the same attenuation regularity with the same attenuation period, i.e. attenuating as per the natural vibration period and stabilizing basically after two periods.

(5) The maximum vibration accelerations of stabilized carbody increase with increasing the riding speed and superelevation gradient of transition curve in rear of intermediate straight line; and the maximum vibration accelerations induced by vertical movement of carbody at the same riding speeds and superelevation gradients are the same.

\section{ACKNOWLEDGEMENTS}

The present work has been supported by the project (51378439) of the National Natural Science Foundation of China and the project (51425804) of the National Science Fund for Distinguished Young Scholars of China. Doctorial Innovation Fund of Southwest Jiaotong University.

\section{REFERENCES}

[1] Si-rong YI. Railway alignment design. Southwest Jiaotong University Press, Chengdu, 2010.

[2] Zeng-jin GONG, Yi-jie FENG. Main technical parameters for plane and vertical section of ballastless track of passenger dedicated line. Journal of Railway Engineering Society, Vol.12, 2007, pp. 170-173.

[3] Temporary Regulations for the Design of the Newly Built Passenge Dedicated Railway with a Speed of $200 \mathrm{~km} / \mathrm{h}$ to $250 \mathrm{~km} / \mathrm{h}$. Ministry of Railways of the People's Republic of China, 2004.

[4] Fei-jian QIU. Study on high-speed railway based on riding comfort. Southwest Jiaotong University Press, Chengdu, 2008.

[5] LONG X Y, WEI Q C, ZHENG F Y. Dynamic analysis of railway transition curves. Proceedings of the Institution of Mechanical Engineers, Part F: Journal of Rail and Rapid Transit, Vol.224, 2010, pp. $1-14$.

[6] Um J H, Choi I Y, Yang S C, et al. Optimization of alignment considering ride comfort for superimposition of vertical and horizontal curves. Proceedings of the Institution of Mechanical Engineers, Part F: Journal of Rail and Rapid Transit, Vol.225, 2011, pp. 649-662.

[7] Zboifiski Krzysztof. Dynamical investigation of railway vehicles on a curved track. European Journal of Mechanics.A/Solids, Vol.17, 1998, pp 1001-1020.
[8] K Miyagaki,M Adachi,Y Sato. Analytical study on effects of form in transition curve. Vehicle System Dynamic, Vol.41, 2004, pp. 657-666.

[9] GAO Liang, QU Cun, QIAO Shen-lu, CAI Xiao-pei, LIU Wei. Analysis on the influencing factors of mechanical characteristics of jointless turnout group in ballasted track of high-speed railway. SCIENCE CHINA, Vol.56, 2013, pp. 499-508.

[10] Biao WANG. Research report on dynamic simulation analysis of the minimum length of intermediate straight line. Key Laboratory of Highspeed Railway Engineering, Ministry of Education, Southwest Jiaotong University, 2014.

[11] Temporary Regulations for the Design of the Newly Built Passenger Dedicated Railway with a Speed of $200 \mathrm{~km} / \mathrm{h}$. Ministry of Railways of the People's Republic of China, 2005.

[12] Foster J.A , Evolutionary computation. Nat. Rev. Genet, Vol.2, 2001, pp. 428-436.

[13] M.Manzan, Genetic optimization of external fixed shading devices. Energy Build, Vol.72, 2014, pp. 431-440. 